\title{
The Influence of Mother's Personality on the Decision about the Elective Cesarean Section: A Pilot Study with a Sample of 16 New Mothers
}

\author{
Franca Aceti ${ }^{1 *}$, Corinna Pancheri ${ }^{1}$, Nicoletta Giacchetti ${ }^{1}$, Vanessa Paladini ${ }^{1}$ and Paola Ciolli ${ }^{2}$
}

${ }^{1}$ Department of Neurology and Psychiatry, Policlinico Umberto I, Sapienza University of Rome, Viale dell'Università 30, 00185 Rome, Italy ${ }^{2}$ Department of Gynaecology, Obstetrics and Urology, Sapienza University of Rome, Viale del Policlinico 155, 00185, Italy

\begin{abstract}
Objective: To investigate the psychological profile of a sample of new mothers, who requested an elective caesarean section (CS), compared with a group of women who had a CS in emergency. Furthermore, the study examined psychiatric, environmental, medical and obstetrical risk factors related to the mother's choice of an elective $\mathrm{CS}$, in order to develop specific intervention strategies.

Methods: A sample of 16 mothers aged $34.88 \pm 8.53$ years were enrolled and assessed using a semi-structured face-to-face interview, the Minnesota Personality Inventory Test-2 (MMPI-2) and the Edinburgh Postnatal Depression Scale (EPDS). The sample was divided in two groups: cases ( 8 women who had an elective CS) and controls (8 women who had a CS in emergency).

Results: The analysis identified a statistical significance among the two groups with a higher prevalence in cases's group of: previous mood disorders (100\% of the cases group), maternal comorbidities (100\% of the cases group), neuroticism (MMPI-2's scale 'NEGE': $p=0.013$ ), 'defensive' attitude (MMPI-2's scale 'K': $p=0.013$ ), hypochondria (MMPI-2' scale 'Hs': $p=0.046$ ), health concerns (MMPI-2's scale 'Hea': $p=0.013$ ) and depression (MMPI-2's scales ' $D$ ': $p=0.012$ and 'Dep': $p=0.023$; EPDS's scores: $p=0.007$ ), with a general tendency to have higher scores of psychopathology $(p=0.033)$. No statistical significance was found concerning socio-demographic information and obstetrical risk factors

Conclusion: Women who chose CS without medical indications showed more somatic anxiety levels, expressed with a hypochondriac rumination and an obsessive way to control their body. This seems associated with more neuroticism and more symptoms of depression which may lead to a higher risk of develop postnatal depression. Gynaecologists should pay attention to the reasons behind the mother's choice of an election CS by ensuring a detailed psychological counselling and try to mitigate levels of anxiety and fears related to the childbirth.
\end{abstract}

Keywords: Caesarean section; Personality; Anxiety; Hypochondria; Minnesota multiphasic personality inventory

\section{Introduction}

The overall rates of caesarean section (CS) are increasing significantly in many parts of the world [1]. In Europe, Italy ranks in the first place among countries with the highest percentage of CS (37.7\%), followed by Portugal (34.8\%) and Hungary (33.4\%) [2].

According to the ACOG (American College of Obstetrics and Gynaecology), the caesarean delivery on maternal request is defined as “... a primary prelabor caesarean delivery on maternal request in the absence of any maternal or fetal indications" [3].

Maternal request is often pointed as one of the key forces driving the worldwide CS increase [4,5]. In Italy, maternal request accounted from $4.5 \%$ to $9 \%$ of all CS performed between 1996-2000 [6].

Although it has been shown that CS, especially if conducted without medical indications, is correlated with more maternal [7] and neonatal $[8,9]$ morbidity and maternal [10] and neonatal [11] mortality, many women still say they prefer it because they consider it a safer procedure instead of vaginal delivery [12].

Many studies in the last years have focused on studying the reasons beyond the choice of a CS without medical indications, and many factors have been discussed. Among these, age of the mother, method of conceiving, tokophobia (fear of childbirth), previous negative birth experience, previous caesarean delivery, complicated pregnancy, low socioeconomic status and low income, low education, have already been identified as influencing factors [13-19]. Furthermore women giving birth by CS on request have shown more often a severe psychiatric disease burden compared with all other women giving birth [20]. In some cases the request may be interpreted like a sign of vulnerability and a real call for help [21]. Also personality may influence a pregnant woman's decision on delivery. Mothers who request an elective CS seemed to be more anxious and more short-tempered (more irritable and more monotony-avoidant) and with less social skills [16].

All these related factors may open a wide range of opportunities to understand more in detail some common issues beyond the CS request and to contribute in managing them in order to reduce the number of CS request without medical indication.

The aims of this pilot study were to investigate:

- Personality of women who requested an elective CS compared with women who had a CS in emergency, using the Minnesota Multiple Personality Inventory-2 (MMPI-2).

*Corresponding author: Franca Aceti, Department of Neurology and Psychiatry, Policlinico Umberto I, Sapienza University of Rome, Viale dell'Università, Rome, Italy, Tel: +393333920910; E-mail: franca.aceti@uniroma1.it

Received November 11, 2016; Accepted November 29, 2016; Published November 30, 2016

Citation: Aceti F, Pancheri C, Giacchetti N, Paladini V, Ciolli P (2016) The Influence of Mother's Personality on the Decision about the Elective Cesarean Section: A Pilot Study with a Sample of 16 New Mothers. Gynecol Obstet (Sunnyvale) 6: 413. doi: 10.4172/2161-0932.1000413

Copyright: (c) 2016 Aceti F, et al. This is an open-access article distributed under the terms of the Creative Commons Attribution License, which permits unrestricted use, distribution, and reproduction in any medium, provided the original author and source are credited. 
- Psychiatric, environmental, medical and obstetrical risk factors related to the mother's choice of an elective CS, in order to develop specific intervention strategies.

\section{Materials and Methods}

\section{Sample}

This case-control study was performed at the obstetric ward of the Department of Gynaecology and Obstetrics affiliated with the Department of Psychiatry of Policlinico Umberto I, Rome, Italy. 18 pregnant women were randomly selected from the Obstetrics ward and invited to participate at the study, 16 of them agreed. Women were included in this study if they were hospitalized and had a CS no more than 3 days before the assessment. All patients included in this study were clinically stable and aged $34.88 \pm 8.53$ years. Women were divided in two groups: cases and controls. The first group was made of 8 women who decided to have an elective CS; the second group was made of 8 women who had a CS in emergency. Exclusion criteria for both groups were:

- Refuse to sign informed consent;

- Age $<18$;

- Diagnosis of mental retardation or schizophrenia;

- Poor knowledge of Italian or other verbal communication limitations that compromised the ability of the subject to follow the research protocol.

At the time of the enrolment, all participants were informed on the nature and objectives of the study and on their specific contribute in practical terms. Enrolment was voluntary and both verbal and written consent were obtained.

\section{Data collection}

All 16 participants were first assessed with a semi-structured faceto-face interview, administered by one researcher (VP), composed by 22 items to collect information about socio-demographic data, the course of pregnancy, previous pregnancies, maternal comorbidities and previous psychiatric diagnosis. Then participants were assessed with:

- The MMPI-2, Italian version [22]. The MMPI-2 is a 567 item, true/false self-report measure of a person's psychological state. It has 10 clinical scales, 8 validity scales, 16 supplemental scales, 15 content scales, 5 PSY-5 scales, 27 content subscales, 28 Harris-Lingoes subscales and 3 social subscales. The 10 clinical scales detect various features including hypochondriasis (Hs), depression (D), hysteria (Hy), psychopathic deviate (Pd), masculinity-femininity (Mf), paranoia $(\mathrm{Pa})$, psychasthenia $(\mathrm{Pt})$, schizophrenia (Sc), hypomania (Ma), and social introversion (Si). The validity scales (cannot say, VRIN, TRIN, FBS, L, F, $\mathrm{K}, \mathrm{S}$ ) consist in assessing the person for lying, defensiveness, faking good and faking bad and among others issues. The supplemental scales are useful to further deepen some clinical characteristics like anxiety (A), repression (R), ego strength (Es), addiction (MAC-R, APS, AAS), hostility (O-H, Ho), dominance (Do), social responsibility (Re), social adaptability $(\mathrm{Mt})$, gender role $(\mathrm{Gm}, \mathrm{Gf})$, presence of post-traumatic stress disorder symptoms (Pk, Ps) and marital distress (MDS). Content scales and subscales help to better describe personality traits like anxiety (Anx), fears (Frs), obsessiveness (Obs), depression (Dep), health concerns (Hea), bizarre mentation (Biz), anger (Ang), cynicism (Cyn), antisocial practices (Asp), low self-esteem (Tpa), social discomfort (Sod), family problems (Fam), work interference (Wrk) and indicators of negative treatment outcome (Trt). PSY-5 scales explore aggressiveness (AGGR), psychoticism (PSYC), disconstraint (DISC), neuroticism (NEGE) and introversion (INTR). According to Butcher, the content scales are believed to have higher face validity and to reflect more homogenous clinical concepts than many of the predecessors in MMPI. All the mentioned scales were used in the present study. After the MMPI-2 was taken and scored by one researcher $(\mathrm{CL})$, an interpretive report was constructed. Scores were converted to what are called normalized "T-scores" on a scale ranging from 30 to 120 . The "normal" range of T-scores is from 50 to 65 . Anything above 65 and anything below 50 is considered clinically significant and open for interpretation $[23,24]$.

- The Edinburgh Postnatal Depression Scale (EPDS), Italian version [25]: A 10-question self-rating scale specifically designed for women who are pregnant or just had a baby. This scale has been proven to be an efficient and effective way to identify patients at risk for perinatal depression. A score equal to or greater than 12 indicates moderate to severe depression. The questionnaire was validated in an Italian version and has a high level of validity, reliability, and internal consistency.

\section{Statistical analysis}

Data were collected and analysed using Microsoft Excel statistics software. Mean scores of MMPI-2 scales were calculated. T-test and Chi-square test were used to calculate statistical significance between variables including MMPI-2 scales scores, EPDS scores, sociodemographic characteristics and clinical information of each group. Statistical significance were agreed for a $\mathrm{p}$-value $<0.05 \%$.

\section{Results}

Sample's mean age was $34.88 \pm 8.53$. As shown in Table 1 , the majority of participants were married or with a stable partner. Additionally, they had mostly high educational levels and most of the participants were employed.

No statistical significance was found among cases vs controls concerning socio-demographic information (Table 1).

As shown in Table 2, statistical significance between the two groups

\begin{tabular}{|c|c|c|c|c|}
\hline$N(\%)$ & $\begin{array}{c}\text { Cases } \\
\mathrm{N}=8\end{array}$ & $\begin{array}{c}\text { Controls } \\
N=8\end{array}$ & $\begin{array}{l}\text { Total } \\
\mathrm{N}=16\end{array}$ & p-value \\
\hline Age (mean) \pm SD & $35.77 \pm 8.97$ & $33.87 \pm 8.56$ & $34.88 \pm 8.53$ & 0.18 \\
\hline \multicolumn{3}{|l|}{ Nationality } & & 0.069 \\
\hline Italian & $8(53.3 \%)$ & $7(46.7 \%)$ & $15(93.7 \%)$ & \\
\hline Others & $0(0 \%)$ & $1(100 \%)$ & $1(6.2 \%)$ & \\
\hline \multicolumn{3}{|l|}{ Marital status } & & 0.241 \\
\hline Married & $7(53.8 \%)$ & $6(46.1 \%)$ & $13(81.2 \%)$ & \\
\hline Unmarried & $1(66.7 \%)$ & $2(33.3 \%)$ & $3(18.7 \%)$ & \\
\hline \multicolumn{3}{|l|}{ Educational level } & & 0.264 \\
\hline Missing/Elementary & $1(33.3 \%)$ & $2(66.7 \%)$ & $3(18.7 \%)$ & \\
\hline High school/University & $7(53.8 \%)$ & $6(46.1 \%)$ & $13(81.2 \%)$ & \\
\hline \multicolumn{3}{|l|}{ Working status } & & 0.934 \\
\hline Unemployed & $1(33.3 \%)$ & $2(66.7 \%)$ & $3(18.7 \%)$ & \\
\hline Housewife & $0(0 \%)$ & $2(0 \%)$ & $2(12.5 \%)$ & \\
\hline Freelance professional & $1(25 \%)$ & $3(75 \%)$ & $4(25 \%)$ & \\
\hline Employee & $6(85.7 \%)$ & $1(14.3 \%)$ & $7(43.7 \%)$ & \\
\hline
\end{tabular}

Table 1: Characteristics of the study population and $\mathrm{p}$-values performed by Chisquare test. 
Citation: Aceti F, Pancheri C, Giacchetti N, Paladini V, Ciolli P (2016) The Influence of Mother's Personality on the Decision about the Elective Cesarean Section: A Pilot Study with a Sample of 16 New Mothers. Gynecol Obstet (Sunnyvale) 6: 413. doi: 10.4172/2161-0932.1000413

Page 3 of 6

was found concerning previous psychiatric diagnosis ( 3 women in the cases group said they had a mood disorder in the past; $\mathrm{p}$-value $=0.0128$ ) and maternal comorbidities (4 women in the cases group and none in the controls group had comorbidities like Hashimoto's disease, chronic hypertension, Meniere's syndrome and Erb's palsy; p-value=0.006). No statistical significance was found concerning the presence of previous abortions or VIP ( 1 woman in the cases group vs 2 women in the controls group) and type of conception (assisted reproductive technology was used by 2 cases and 1 control). Of the whole sample, just 1 woman in the control group was multiparous.

Concerning the psychological profile investigated using the MMPI-2, it was found a general tendency to have higher scores of psychopathology in women in the cases group $(\mathrm{p}=0.033)$. Some differences were found between groups comparing mean scores of the 10 clinical scales and the 8 validity scales of each group (Figures 1 and 2). Particularly, the greatest differences were found between (Table 3):

- Mean scores of scale S (mean in cases group: 41.75 , mean in controls group: 49.25 ) and scale $\mathrm{K}$ (mean score in cases group: 42.37, mean score in controls group: 51).

- Mean scores of scale Hs (mean in cases group: 53.5, mean in controls group: 45.87 ) and scale Pt (mean in cases group: 50.5, mean in controls group: 42.74).

Statistically significant differences between the two groups

\begin{tabular}{|c|c|c|c|}
\hline $\mathbf{N}(\%)$ & Cases N=8 & Controls N=8 & Total N=16 \\
\hline Vip/abortion & $1(33.3 \%)$ & $2(66.7 \%)$ & $3(18.7 \%)$ \\
\hline Mood disorders & $3(100 \%)$ & 0.264 & $3(18.7 \%)$ \\
\hline Maternal comorbidity & $4(100 \%)$ & $0(0 \%)$ & $4(25 \%)$ \\
\hline Type of conception & & & \\
\hline Natural & $6(46.1 \%)$ & $7(53.8 \%)$ & $13(81.2 \%)$ \\
\hline $\begin{array}{c}\text { By assisted reproductive technology } \\
\text { (ART) }\end{array}$ & $2(66.7 \%)$ & $\mathbf{0 . 0 0 6 7 ^ { * }}$ & \\
\hline
\end{tabular}

*=statistical significance.

Table 2: Descriptive analysis of women in the two study groups, performed by Chi-square test.
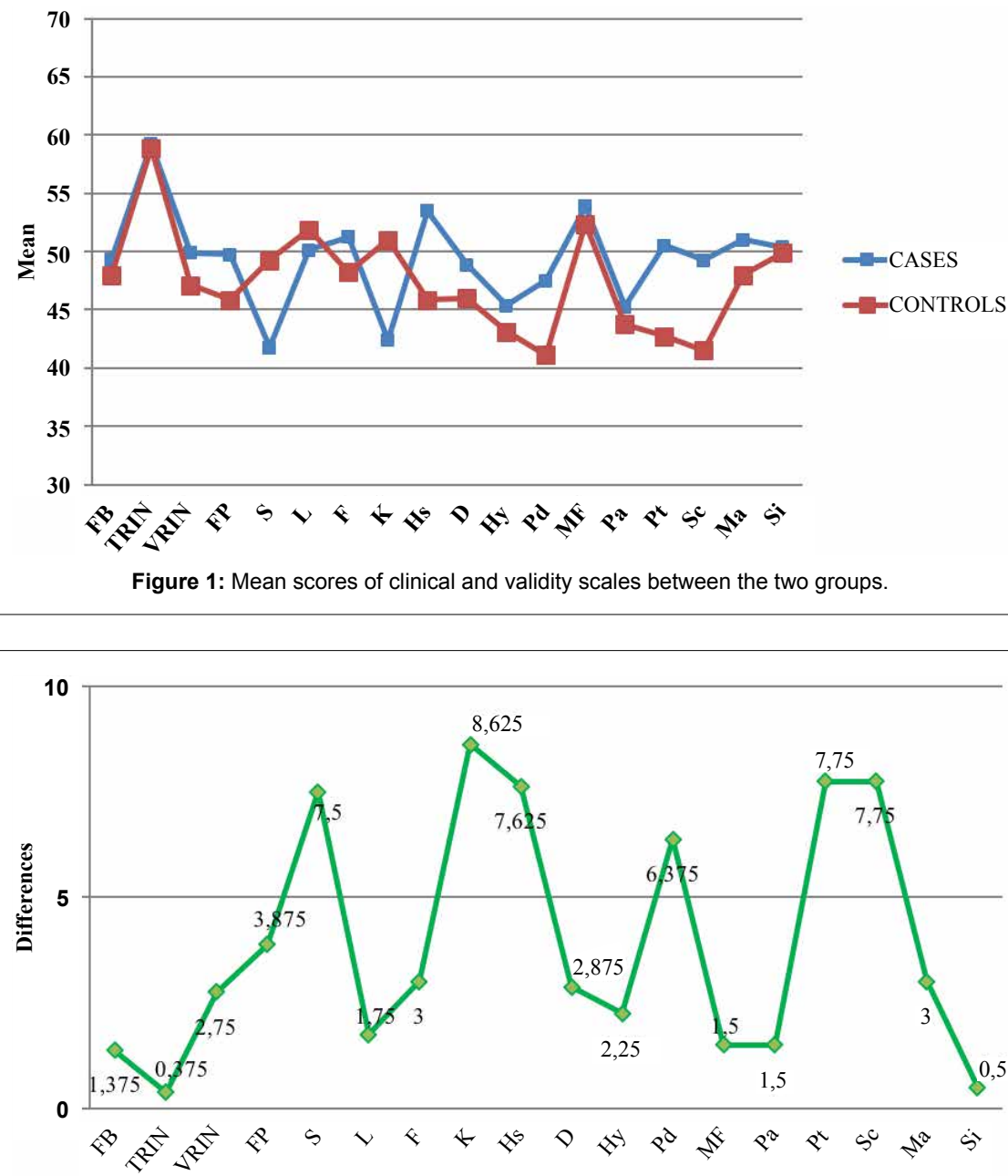

Figure 2: Differences between mean scores of validity and clinical scales. 
Citation: Aceti F, Pancheri C, Giacchetti N, Paladini V, Ciolli P (2016) The Influence of Mother's Personality on the Decision about the Elective Cesarean Section: A Pilot Study with a Sample of 16 New Mothers. Gynecol Obstet (Sunnyvale) 6: 413. doi: 10.4172/2161-0932.1000413

Page 4 of 6

were found regarding MMPI-2 scores which crossed the "normal" range. Compared to controls, women in cases group had more frequently clinically significant scores concerning the following psychopathological characteristics (Table 4 and Figure 3):

- Depression (scale D, p=0.012; scale Dep, $\mathrm{p}=0.023$ );

- Neuroticism (scale NEGE, $\mathrm{p}=0.013$ );

- Manic state (scale Ma, $\mathrm{p}=0.046$ );

- Hypochondria (scale Hs, $\mathrm{p}=0.013$ );

- Health concerns (scale Hea, $\mathrm{p}=0.046$ );

- 'Defensive' attitude (scale K, $\mathrm{p}=0.013$ ).

No statistically significant differences were found in others MMPI2 scales between groups.

Concerning data about EPDS questionnaire, it was found that
$43.75 \%$ of the whole sample crossed the EPDS's cut-off for moderate to severe depression (score $>12$ ). Mean score in women who crossed the cut-off was 15, mean score in women who didn't cross the cut-off was 3.78. As shown in (Table 5 and Figure 4), the cut-off for depression was crossed by 6 women in the cases group (85.71\%) and just 1 woman in the controls group (14.29\%) showing a statistical significance for the EPDS depression variable $(\mathrm{p}=0.0072)$.

\section{Conclusion}

Caesarean delivery on maternal request has a multifactorial genesis, including social, cultural, medical and psychological factors. Particularly, psychological factors seem to strongly influence this important choice which consists in undergoing a surgical procedure in the absence of any maternal or fetal indications and correlated with more morbidity and mortality compared to the vaginal delivery [7-11]. The most common reasons behind this choice are tokophobia $[13,14,16]$ and previous or referred negative birth experience [17],

\begin{tabular}{|c|c|c|c|c|}
\hline & Scale S & Scale $\boldsymbol{S}$ & Scale Hs \\
\hline Cases & 41.75 & 42.37 & 53.5 & 50.5 \\
\hline Controls & 49.25 & 51 & 45.87 & 72.75 \\
\hline Difference & 7.5 & 8.3 & 7.6 \\
\hline
\end{tabular}

Table 3: MMPI-2's clinical and validity scales: mean scores and differences between the two groups

\begin{tabular}{|c|c|c|c|c|}
\hline $\mathbf{N}(\%)$ & Cases $\mathrm{N}=8$ & Controls $\mathrm{N}=8$ & Total $\mathrm{N}=16$ & p-value \\
\hline Scale $D$ & $2(100 \%)$ & $0(0 \%)$ & $2(12.5 \%)$ & $0.012^{*}$ \\
\hline Scale Dep & $5(83.3)$ & $1(16.6 \%)$ & $6(37.5 \%)$ & $0.023^{*}$ \\
\hline Scale NEGE & $3(100 \%)$ & $0(0 \%)$ & $3(18.7 \%)$ & $0.013^{*}$ \\
\hline Scale $M a$ & $4(80 \%)$ & $1(20 \%)$ & $5(31.2 \%)$ & $0.046^{*}$ \\
\hline Scale Hs & $3(100 \%)$ & $0(0 \%)$ & $3(18.7 \%)$ & $0.013^{*}$ \\
\hline Scale Hea & $4(80 \%)$ & $1(20 \%)$ & $5(31.2 \%)$ & $0.046^{*}$ \\
\hline Scale $K$ & $3(100 \%)$ & $0(0 \%)$ & $3(18.7 \%)$ & $0.013^{*}$ \\
\hline
\end{tabular}

${ }^{*}=$ statistical significance.

Table 4: Frequency of clinically significant scores on different MMPI-2's scales, between cases vs controls. P-value performed by T-test.

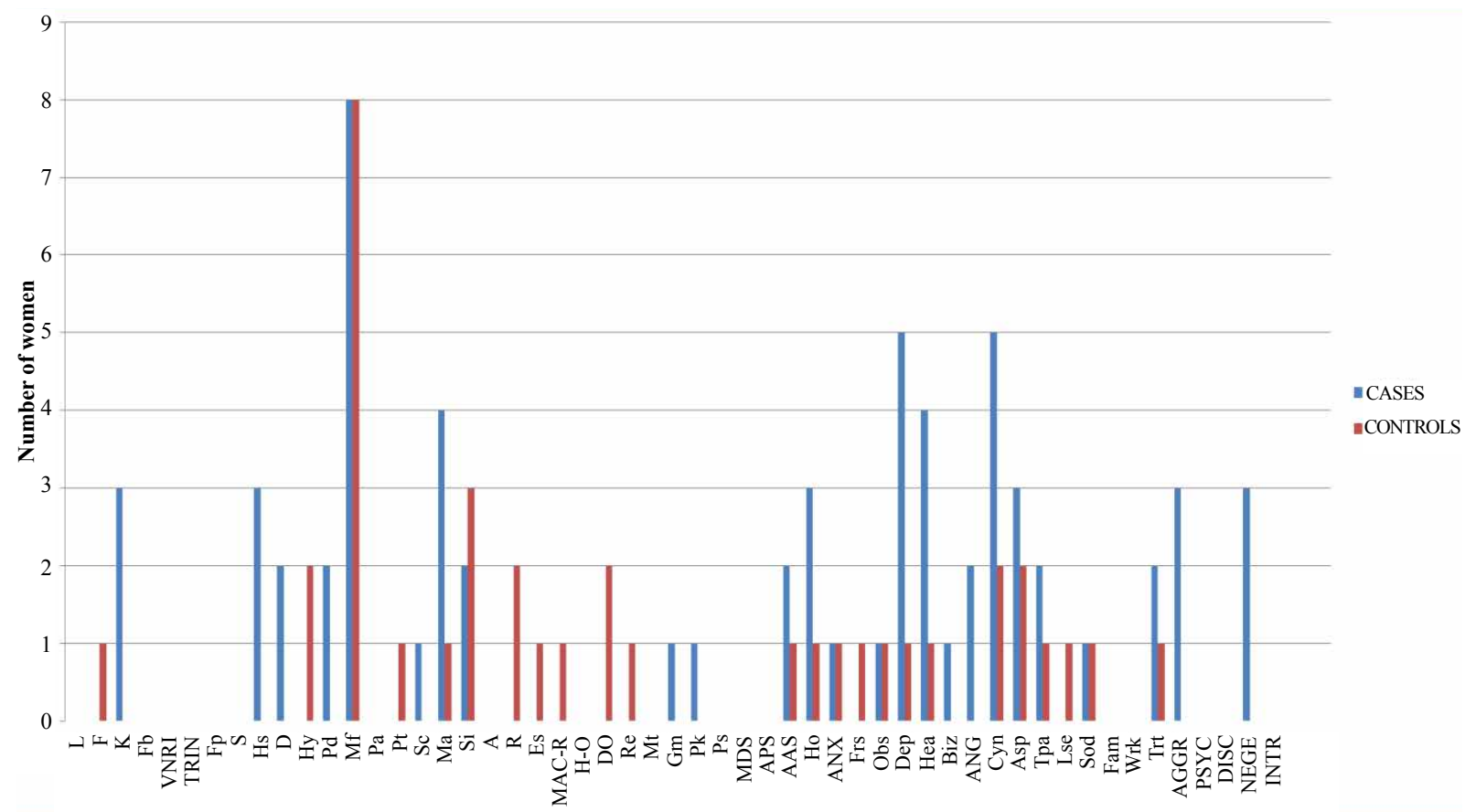

Figure 3: Number of women who obtained clinically significant scores at MMPI-2 scales: cases vs controls. 


\begin{tabular}{|c|c|c|c|c|}
\hline & Sample N (\%) & Cases N (\%) & Controls N (\%) & p-value \\
\hline $\begin{array}{c}\text { EPDS } \\
\text { score }\end{array}$ & & & & $0.0072^{*}$ \\
\hline$<12$ & $9(56.2 \%)$ & $2(22.2 \%)$ & $7(77.8 \%)$ & \\
\hline$\geq 12$ & $7(43.7 \%)$ & $6(85.7 \%)$ & $1(14.3 \%)$ & \\
\hline
\end{tabular}

*=statistical significance.

Table 5: EPDS scores differences in the two groups, performed by Chi-square test.

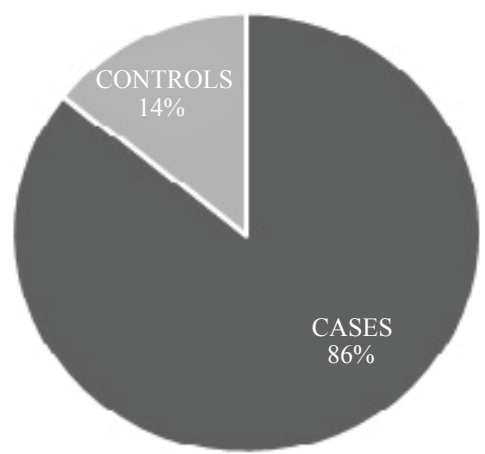

Figure 4: Prevalence of post-partum moderate-severe depression in cases $(\mathrm{N}=8)$ vs controls $(\mathrm{N}=8)$.

but these motivations need more detailed psychological explanations. In recent studies about this topic, mothers who requested an elective CS seemed to be more anxious, depressed, irritable and with low selfesteem and more somatization problems [16,20].

This work helped to better understand psychological and psychopathological differences between a group of primiparous women who requested a CS in election and a group of women who had a CS in emergency, in which just one was multiparous. Multiparty seemed not to be involved in the previous results. One of the identified differences between the two groups was that the first group had higher levels of somatic anxiety, expressed by higher scores on the MMPI-2 hypochondria scale (Hs). In these women, this kind of body-related anxiety seems to be expressed with a hypochondriac rumination and an obsessive way to control their body. Mothers in cases group had also higher scores on the MMPI-2 neuroticism scale (NEGE) which means more anxiety, pessimism and self-doubt. Looking at the MMPI2 validity scales ( $\mathrm{S}$ and $\mathrm{K}$ scales), a 'defensive' approach was also noted in these women. This could mean that women who choose an elective caesarean delivery tend not to live openly their feelings, experiencing them just in a concrete and practical way without being able to symbolize them. Planning the delivery, removing every physiological worry related to the vaginal delivery, is an example of their 'defensive' and 'avoidant' attitude. It is probably for this reason that these mothers prefer to choose a less-involving, surgical procedure, regardless of his well-known dangerousness, instead of a natural childbirth. The birthevent may appear to them as overly emotional and not controllable.

Concerning depression, results from MMPI-2 and EPDS scores matched. Women of the cases group have a more depressive personality experimenting more depressive feelings which means a higher risk to develop depression in the post-partum period. Some specific characteristics of personality, in fact, seem to have a key role in clinical manifestations of perinatal depression. For this reason, it is important to detect them to identify mothers at risk and to plan targeted therapeutic interventions [26-28]. Furthermore, the presence in the cases group of a more frequent history of past mood disorders, point up the vulnerability of these women to head into depression.
Despite the limit of a small sample, this pilot study has led to focus more in detail the psychological characteristics of mothers who request CS without medical indication. Further studies with a larger sample could consolidate these findings. Furthermore, to get over the bias of an altered psychological state immediately after the CS, it would be interesting to assess the same women a certain period of time after the delivery, to verify the consistency of the results.

In conclusion, a detailed psychological counselling in mothers who express the wish to have a CS without medical indications should be considered and integrated in the standard gynaecological counselling. Particularly the gynaecologist, besides explaining the dangerousness of the surgical procedures, should:

- Explore the reasons behind the woman's decision of CS, trying to detect women at risk for postnatal depression;

- Try to reduce conflicts originating from the decision about delivery;

- Try to mitigate levels of anxiety and fear related to the childbirth;

- Improve the mother's subjective satisfaction about the birthevent also promoting a closer mother-child relationship.

\section{References}

1. Lavender T, Hofmeyr GJ, Neilson JP, Kingdon C, Gyte GM (2012) Caesarean section for non-medical reasons at term. UK: John Wiley \& Sons, Ltd.

2. OECD (2013) Caesarean sections (indicator).

3. American College of Obstetricians and Gynaecologists (2013) ACOG committee opinion no. 559: Caesarean delivery on maternal request. Obstet Gynecol 121: 904-907.

4. Kiran TSU, Jayawickrama NS (2002) Who is responsible for the rising caesarean section rate?. J Obstet Gynaecol 22: 363-365.

5. Jackson NV, Irvine LM (1998) The influence of maternal request on the elective caesarean section rate. J Obstet Gynaecol 18: 115-119.

6. Tranquilli A, Giannubilo S (2004) Cesarean delivery on maternal request in Italy. Int J Gynecol Obstet 84: 169-170.

7. Murphy DJ, Liebling RE, Verity L, Swingler R, Patel R (2001) Early maternal and neonatal morbidity associated with operative delivery in second stage of labour: a cohort study. Lancet 358: 1203-1207.

8. Dahlgren LS, von Dadelszen P, Christilaw J, Janssen PA, Lisonkova S, et al (2009) Caesarean section on maternal request: risks and benefits in healthy nulliparous women and their infants. J Obstet Gynaecol Can 31: 808-817.

9. Hansen AK, Wisborg K, Uldbjerg N, Henriksen TB (2007) Elective caesarean section and respiratory morbidity in the term and near-term neonate. Acta Obstet Gynecol Scand 86: 389-394.

10. Ecker JL (2004) Once a pregnancy, always a cesarean? Rationale and feasibility of a randomized controlled trial. Am J Obstet Gynecol 190: 314-318.

11. MacDorman MF, Declercq E, Menacker F, Malloy MH (2006) Infant and Neonatal Mortality for Primary Cesarean and Vaginal Births to Women with \&quot;No Indicated Risk,\&quot; United States, 1998-2001 Birth Cohorts. Birth 33: 175-182.

12. Souza J, Gülmezoglu A, Lumbiganon P, Laopaiboon M, Carroli G, et al. (2010) Caesarean section without medical indications is associated with an increased risk of adverse short-term maternal outcomes: the 2004-2008 WHO Global Survey on Maternal and Perinatal Health. BMC Med 8: 71.

13. Sahlin M, Carlander-Klint AK, Hildingsson I, Wiklund I (2013) First-time mothers wish for a planned caesarean section: Deeply rooted emotions. Midwifery 29 447-452.

14. Wiklund I, Edman G, Andolf E (2007) Cesarean section on maternal request reasons for the request, self-estimated health, expectations, experience of birth and signs of depression among first-time mothers. Acta Obstet Gynecol Scand 86: $451-456$ 
Citation: Aceti F, Pancheri C, Giacchetti N, Paladini V, Ciolli P (2016) The Influence of Mother's Personality on the Decision about the Elective Cesarean Section: A Pilot Study with a Sample of 16 New Mothers. Gynecol Obstet (Sunnyvale) 6: 413. doi: 10.4172/2161-0932.1000413

Page 6 of 6

15. Handelzalts JE, Fisher S, Lurie S, Shalev A, Golan A, et al. (2012) Personality, fear of childbirth and cesarean delivery on demand. Acta Obstet Gynecol Scand 91: 16-21.

16. Ryding EL, Wirfelt E, Wängborg IB, Sjögren B, Ryding EL, et al. (2007) Personality and fear of childbirth. Acta Obstet Gynecol Scand 86: 814-820.

17. Ryding EL, Lukasse M, Parys AS, Wangel AM, Karro H, et al. (2015) Fear of Childbirth and Risk of Cesarean Delivery: A Cohort Study in Six European Countries. Birth 42: 48-55.

18. Fuglenes D, Aas E, Botten G, Øian P, Kristiansen IS (2011) Why do some pregnant women prefer cesarean? The influence of parity, delivery experiences, and fear. Am J Obstet Gynecol 205: 45.e1-45.e9.

19. Lerner-Geva L, Glasser S, Levitan G, Boyko V, Golan A, et al. (2015) A casecontrol study of caesarean delivery on maternal request: who and why? J Matern Neonatal Med 29: 2780-2785

20. Sydsjö G, Möller L, Lilliecreutz C, Bladh M, Andolf E, et al. (2015) Psychiatric illness in women requesting caesarean section. BJOG An Int J Obstet Gynaecol 122: 351-358.

21. Dweik D, Sluijs AM (2015) What is underneath the cesarean request? Acta Obstet Gynecol Scand 94: 1153-1155.
22. Butcher JN, Graham JR, Ben-Porath YS (2011) Minnesota Multiphasic Personality Inventory ${ }^{\circledR}-2$. Roma: Giunti Testing.

23. Butcher JN, Dahlstrom WG, Graham JR, Tellegen AM, Kreammer B (1989) The Minnesota Multiphasic Personality Inventory-2 (MMPI-2) Manual for Administration and Scoring. Minneapolis, MN: University of Minneapolis Press.

24. Leone C (2016) Manuale per il MMPI-2 - nella pratica clinica. Roma: Alpes.

25. Benvenuti P, Ferrara M, Niccolai C, Valoriani V, Cox JL (1999) The Edinburgh Postnatal Depression Scale: validation for an Italian sample. J Affect Disord 53: $137-141$

26. Aceti F, Aveni F, Baglioni V, Carluccio GM, Colosimo D, et al. (2012) Perinata and postpartum depression: From attachment to personality. A pilot study. Journal of Psychopathology 18: 328-334.

27. Aceti F, Carluccio GM, Meuti V, Piperno F, Sogos C, et al. (2012) Parental care and post partum depression: a case report. Riv Psichiatr 47: 221-225.

28. Meuti V, Marini I, Grillo A, Lauriola M, Leone C, et al. (2014) MMPI-2: Cluster Analysis of Personality Profiles in Perinatal Depression-Preliminary Evidence. Sci World J 2014: 1-10.
Citation: Aceti F, Pancheri C, Giacchetti N, Paladini V, Ciolli P (2016) The Influence of Mother's Personality on the Decision about the Elective Cesarean Section: A Pilot Study with a Sample of 16 New Mothers. Gynecol Obstet (Sunnyvale) 6: 413. doi: 10.4172/2161-0932.1000413
OMICS International: Open Access Publication Benefits \&

\section{Features}

Unique features:

- Increased global visibility of articles through worldwide distribution and indexing

- Showcasing recent research output in a timely and updated manner

- Special issues on the current trends of scientific research

Special features:

- $700+$ Open Access Journal

$50,000+$ Editorial team

Rapid review process

Quality and quick editorial, review and publication processing

Indexing at major indexing services

- Sharing Option: Social Networking Enabled

Authors, Reviewers and Editors rewarded with online Scientific Credits

Better discount for your subsequent articles

Submit your manuscript at: http://www.omicsgroup.org/iournals/submission 